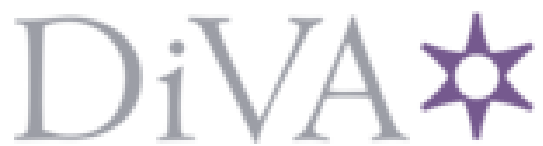

http://www.diva-portal.org

This is the published version of a paper published in .

Citation for the original published paper (version of record):

Adane, T F., Nicolescu, M. (2014)

System dynamics analysis of energy usage: Case studies in automotive manufacturing

International Journal of Manufacturing Research, 9(2): 131-156

https://doi.org/10.1504/IJMR.2014.062440

Access to the published version may require subscription.

N.B. When citing this work, cite the original published paper.

Permanent link to this version:

http://urn.kb.se/resolve?urn=urn:nbn:se:kth:diva-161011 


\title{
System dynamics analysis of energy usage: case studies in automotive manufacturing
}

\section{Tigist Fetene Adane* and Mihai Nicolescu}

\author{
Department of Production Engineering, \\ Royal Institute of Technology, \\ Division of Machine and Process Technology, \\ Brinellvägen 68, 10044 Stockholm, Sweden \\ E-mail: tigist@kth.se \\ *Corresponding author
}

\begin{abstract}
Our life is strongly linked with the usage of natural resources. With increase in world population and welfare there is an increasing global demand for raw material. Energy is a necessity in everyday life and is often generated using non-renewable natural resources which are finite. Manufacturing is one of the largest energy and material resource consumers. There is great concern about minimising consumption of energy in manufacturing industry to sustain the natural carrying capacity of the ecosystem. This is one of the challenges in today's industrial world. The paper presents the application of system dynamics theory for modelling and simulation of complex manufacturing processes. The simulations help to understand the intricate nature of the interrelation of process parameter and to make sound decision about minimising the energy losses. Two case studies are presented, one in cylinder head casting processes and the other in crankshaft machining. The developed models provide an insight into how to select critical operations and to identify the effect of various parameters on the energy consumption. Also, the models help to understand how changes of parameters over time affect the behaviour of energy changes. The outcome of this research enables the company to identify potential avenues to minimise energy usage and offers a decision support tool.
\end{abstract}

[Received 3 June 2013; Revised 31 August 2013; Accepted 13 October 2013]

Keywords: system dynamics; sustainable manufacturing; energy efficient manufacturing; energy consumption; crank shaft; cylinder head.

Reference to this paper should be made as follows: Adane, T.F. and Nicolescu, M. (2014) 'System dynamics analysis of energy usage: case studies in automotive manufacturing', Int. J. Manufacturing Research, Vol. 9, No. 2, pp.131-156.

Biographical notes: Tigist Fetene Adane received her MSc in Production Engineering from Royal Institute of Technology, KTH, Sweden, in 2011. Currently, she is pursuing her Doctoral degree in Production Engineering under Machine and Process Technology division at KTH. Her research work involves developing simulation modelling for evaluation of machining strategy.

Mihai Nicolescu is a Professor. He is chairing the Machine and Process Technology Division at the KTH, Royal Institute of Technology. He has a wide experience in education and research in manufacturing area. He coordinates research in several European and National RTD projects. He has published several papers in area of machining dynamics, process modelling and papers related to remanufacturing. 
This paper is a revised and expanded version of a paper entitled 'System dynamics analysis of energy usage: case studies in automotive manufacturing' presented at The 5th International Swedish Production Symposium, SPS12, Linköping, Sweden, November 2012.

\section{Introduction}

Energy, water and material resources are fundamental to human welfare and economic wealth. The way in which these resources are used creates pressures on the environment.

Among all economic sectors manufacturing is of high importance to the world economy, with a huge potential to generate wealth, jobs and a better quality of life. Meantime, manufacturing industry is one of the economic sectors contributing most to the waste generation. It accounts for about $75 \%$ of the world's yearly coal consumption, $44 \%$ of the world's natural gas consumption, and $20 \%$ of global oil consumption. In addition, these manufacturing companies also use $42 \%$ of all the electricity generated (IEA, 2004). For each individual country, energy consumed by the industrial sector is also a principle concern since it does constitute a large part/segment of total energy consumption. According to European Union Statistics in 2007 in Europe, 27.9\% of energy consumption by sector was used by industry, out of which $12.8 \%$ was consumed by Sweden's Industry. According to this same study, Sweden's industrial sector was responsible for $38 \%$ of the country's total energy consumption.

Growth in the manufacturing industry is boosting the extraction and use of natural resources in order to generate/meet each society's own energy and material demands. Energy and material are of such great importance for each society since it is necessary towards economic development and growth. Here, however, the vital resources of our planet remain limited.

Consequently, there is great concern about minimising consumption of energy and material (resources) in manufacturing industry as well as sustaining the natural carrying capacity of the corresponding ecosystem. This is one of the important challenges for today's industrial world.

Due to growing public awareness about environmental and sustainability matters, industries are increasingly under pressure to focus on sustainability. According to the Brundtland (1987) report sustainability is "development that meets the needs of the present without compromising the ability of future generations to meet their own needs".

As defined by the US Department of Commerce sustainable manufacturing is "the creation of manufactured products that use processes that minimize negative environmental impacts, conserve energy and natural resources, are safe for employees, communities, and consumers and are economically sound". Hence, sustainability is a multidimensional concept and includes environmental, financial and social aspects.

In manufacturing industry, energy consumption and losses, material waste and polluting emissions are the most prominent concerns also being linked to one another. For instance, emissions of $\mathrm{CO}_{2}$ and other greenhouse gases are closely associated to energy issues. In order to control emissions, it is crucial to provide solutions, which are efficient especially concerning energy production and consumption.

In order to make sound decisions to reduce the energy and material losses in manufacturing processes, it is important to identify and understand the interrelation 
between the factors characterising the nature of the process. SD is suitable for this kind of modelling. This paper introduces the system dynamics (SD) theory to model and simulate the complex nature of the dynamic interaction between factors characterising manufacturing processes. On account of SD is suitable for industrial modelling and policy making issue like environmental and energy management. Rather than studying each object separately, SD is suitable to study objects as a whole to understand how the factors interact each other as a part of a system (Brailsford et al., 2004; Azar, 2012). The main scope is to oversee the possibility of minimising energy losses within the manufacturing processes by simulating each step in the operation chain of transforming raw material into a final/intermediate product. The adopted methodology is demonstrated through two case studies with data collected from two separate manufacturing plants. In the first case study, the main focus is on identifying processes having the highest energy consumption rates in the production system. SD modelling and simulation technique were used to model selected processes in order to understand their behaviour impact linked to energy consumption and emission levels. Regarding the second case, waste of material during cutting operations was also taken into consideration in the modelling.

Overall, the ultimate objective is to identify potential areas in the processes where energy can be saved and also provide a decision support tool to help minimise energy consumption.

This paper constitutes eight sections including introduction. The second section describes the comparison of different simulation modelling techniques (tools) of related studies. The main reason why SD chose is also explicitly explained. Section 3 introduces an overview of SD. The terminology of SD modelling used to build the modelling process, and its mathematical formulation is also described. The software used is also mentioned. The fourth section presents the benefit of SD modelling and simulation application in manufacturing process. It presents recommended areas to use SD. It also describes an approach used to develop an SD model. In Section 5, an overview of sand mould casting process, steps of crankshaft machining for the given company and step of melting process is explained.

Section 6 describes the cases of two automotive manufacturing companies. It describes the identification of most energy intensive operation and their influential parameter. In addition it describes the energy input, consumption in the system and losses from the system. Moreover, it introduces possible ways of heat losses during production. At last the model that comprises of parameters of selected operation of energy input, output, losses are developed. The seventh section describes the results obtained from this research work. The results come from simulation of the model developed. The last section concludes the work presented in this work.

\section{Manufacturing process modelling}

\subsection{Related studies}

Many companies use simulation as an aid in their decision-making process. According to a classic definition of simulation, "simulation involves designing a model of a system and carrying out experiments on it as it progresses through time. It is possible to see in a model how a real-world activity will perform under different conditions and test various hypotheses at a fraction of the cost of performing the actual activity" (Camdali and Tunc, 
2006). A crucial point in this regard for companies is to decide which simulation approach fits their system best.

Simulation of manufacturing systems can be performed either by discrete event or continuous state (Leemis and Steve, 1994). Özgün and Barlas (2009) point out that discrete event simulation (DES) is suitable for problems in which variables change in discrete times and by discrete steps. On the other hand, continuous simulation is suitable for systems in which the variables can change continuously (Baines and Harrison, 1999). $\mathrm{SD}$ is an approach suitable for continuous type of simulation where feedback significantly affects the behaviour of the system in which producing dynamic changes in system behaviour.

Kibira et al. (2009) state that typically DES is done to address a particular set of problems, and it does some 'what if' analyses. It focuses on streamlining and validating processes, reducing costs, and meeting schedules; not the identification and evaluation of environmentally friendly alternatives (Sterman, 2000). Therefore, it seldom addresses sustainability issues in manufacturing.

Unlike DES, SD is often used for strategic and policy related applications (Crespo-Márquez et al., 1993). This is because of the high abstraction level of the models and the longer simulation time horizon used to reveal the dynamic behaviour (Lin et al., 1998; Maani and Cavana, 2007; Tesfamariam and Lindberg, 2005).

Tako and Robinson (2009) summarised the literatures that have been done regarding the comparison of DES and SD modelling in Table 1.

Table 1 Comparison between SD and DES modelling

\begin{tabular}{|c|c|c|c|}
\hline Author(s) & Aspect compared & $S D$ & $D E S$ \\
\hline $\begin{array}{l}\text { Sweetser (1999), and } \\
\text { Lane (2000) }\end{array}$ & $\begin{array}{c}\text { Nature of problems } \\
\text { modelled }\end{array}$ & Strategic & Tactical/operational. \\
\hline $\begin{array}{l}\text { Coyle (1985), } \\
\text { Sweetser (1999), and } \\
\text { Brailsford and } \\
\text { Hilton (2001) }\end{array}$ & Feedback effects & $\begin{array}{l}\text { Models causal } \\
\text { relationships and } \\
\text { feedback effects. }\end{array}$ & $\begin{array}{c}\text { Models open loop } \\
\text { structures-less } \\
\text { interested in feedback. }\end{array}$ \\
\hline $\begin{array}{l}\text { Baines et al. (1998) } \\
\text { and Lane (2000) }\end{array}$ & System representation & Holistic view & Analytic view \\
\hline Lane (2000) & Complexity & $\begin{array}{l}\text { Wider focus, general } \\
\text { and abstract systems }\end{array}$ & $\begin{array}{l}\text { Narrow focus with } \\
\text { great complexity and } \\
\text { detail }\end{array}$ \\
\hline $\begin{array}{l}\text { Sweetser (1999) and } \\
\text { Brailsford and } \\
\text { Hilton (2001) }\end{array}$ & Data inputs & $\begin{array}{l}\text { Quantitative and } \\
\text { qualitative, use of } \\
\text { anecdotal data }\end{array}$ & $\begin{array}{l}\text { Quantitative based on } \\
\text { concrete processes }\end{array}$ \\
\hline $\begin{array}{l}\text { Meadows (1980) and } \\
\text { Mak (1993) }\end{array}$ & Model results & $\begin{array}{l}\text { Provides a full picture } \\
\text { (qualitative and } \\
\text { quantitative) of } \\
\text { system performance }\end{array}$ & $\begin{array}{l}\text { Provides statistically } \\
\text { valid estimates of } \\
\text { system performance }\end{array}$ \\
\hline
\end{tabular}

Source: Tako and Robinson (2009)

In their research, Kibira et al. (2009) proposed SD methodology for modelling and analysis of sustainable manufacturing. Their proposed framework organises factors 
influencing sustainable manufacturing into four interacting complex domains: manufacturing, environmental, financial and social. They aim at making the framework into a platform that can be used by different industries.

Commonality between the mentioned researches is that these models are developed at system level. That is to say that they take a holistic view into account and consider different domains in manufacturing.

Despite evidence that SD is suitable for industrial modelling; in the literature survey done by Baines and Harrison (1999), there were not many applications of SD in manufacturing at process level out of 80 papers surveyed only $10 \%$ were placed in the operation level. Up to date, there are very limited studied have conducted on energy analysis in the manufacturing industry using SD simulation and modelling technique. However, this technique has been applied widely used in other areas such as supply chain, health care, business management, tourism, etc. This also motivated the current research work and directed it towards modelling of casting and machining operations as a system at process level.

\section{Manufacturing process simulation}

\subsection{SD overview}

SD is a powerful methodology and computer simulation modelling technique for framing, understanding, and discussing complex issues and problems. It was originally developed in the mid-1950s by Professor Jay W. Forrester at the Massachusetts Institute of Technology to help corporate managers improve their understanding of industrial processes.

SD is a method for studying the world around us. It is used to study objects as a whole to understand how they interact with each other as part of a system, instead of studying each object separately. In complex systems like manufacturing, objects often create feedback loops, where a change in one variable affects other variables dynamically, which feedbacks to the original object, and so on. The interplays among objects determine the different states the system can assume in the course of time, which is known as the dynamic behaviour of the system (Tesfamariam and Lindberg, 2005). The dynamic complexity of the system arises not from the amount of the system's component, but from the combination of interactions among system elements over time (Brailsford et al., 2004; Azar, 2012). See an example in Figure 1, how the dynamic complexity results. An increase in production rate increases the inventory and if inventory increases, then shipment rate also increases. In other case, an increase in shipment rate lowers the amount in the inventory, hence results in higher production rate. That is a change on one factor affect others and feedback each other, it shows how a dynamic complexity observed in the system. There are two types of feedback loop - negative or balancing loop (B) and positive or reinforcing $(R)$ loop).

A SD model is useful in illustrating how the real system behaves and to check what will happen if some parameter in the model is changed over a period of time. 
Figure 1 Example of a causal loop diagram

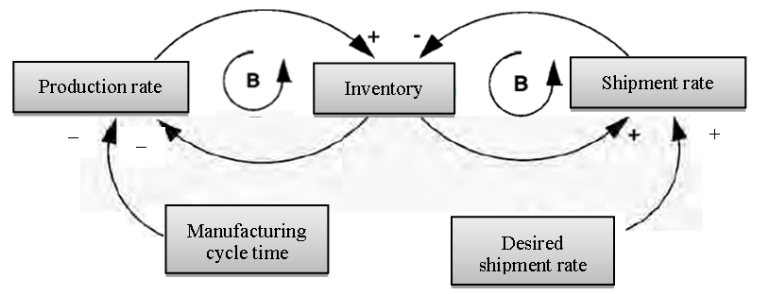

Source: Sterman (2000)

It is important to notice that in SD varying the value of a parameter does not mean considering only one factor at a time as is the case in one-factor-at-a-time (or OFAT) method, neither it means changing one parameter and freezing others as is the case in design of experiments (DoE). Since a change in one, results in change in others as parameters are already linked and interrelated.

Some commercial software program are available that were designed to facilitate the building and use of SD models (in this case to study the interrelation of the process). The most widely used are Stella/iThink, Vensim, Powersim and AnyLogic. Stella/iThink has been used to build the model presented in this paper (Azar, 2012; Ford, 2009).

\subsection{Terminology of SD modelling}

Following Table 2 are the four building blocks used in modelling process along with their definition. It presented in a stock and flow diagram and an example of hydraulic metaphor also illustrated in Figure 2.

Table 2 Four building blocks of SD and its definition

\begin{tabular}{ll}
\hline Building block & Definition of the term \\
\hline Stock & Something that accumulates \\
Flow & $\begin{array}{l}\text { Activity that changes magnitude of stock by adding to it (inflow) or } \\
\text { subtracting from it (outflow) }\end{array}$ \\
Converter & $\begin{array}{l}\text { Stores equation or constant; does not accumulate } \\
\text { Connector }\end{array}$ \\
\hline
\end{tabular}

Source: Sterman (2000)

Figure 2 Stock and flow diagram, (a) general structure (b) manufacturing flow (see online version for colours)

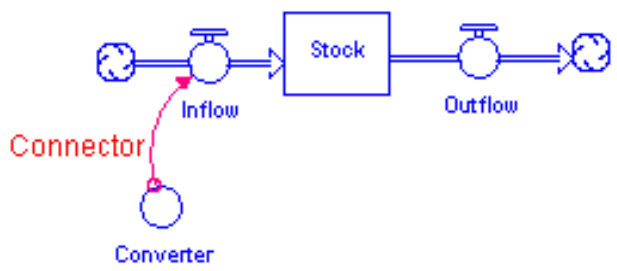

(a)

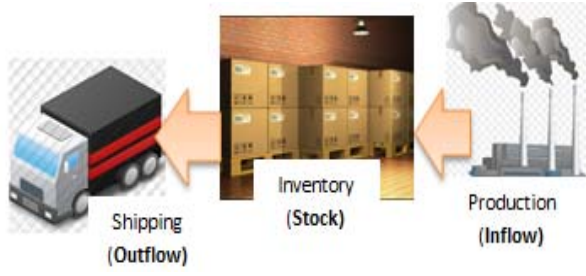

(b)

Source: Sterman (2000) 


\subsection{Mathematical formulation}

SD models involve a set of coupled, non-linear differential equations of the form (Forrester, 1961; Kirkwood, 2013; Sterman, 2000):

$$
d x / d t=f(x(t), p)
$$

where

$x(t)$ is a vector of levels (stocks or state variables)

$p \quad$ is a set of parameters

$f \quad$ is a non-linear vector valued function.

The SD simulation of the system can be easily accomplished by dividing the simulation time discretely into $d t$ with steeping of an interval $d t$. Sequentially, not to bring visible effect on the dynamic behaviour pattern shown on the model, the computational interval $d t$ should be as small as possible. The state variable $x(t)$ at each step is calculated from the earlier value $x(t-d t)$ and from its net rate of change $x^{\prime}(t)$; that is $x(t)=x(t-d t)+d t * x^{\prime}(t-d t)$.

In the manufacturing flow example, inflow is the flow of finished product into the inventory that is the rate at which product is entered into the inventory. Whereas outflow is the shipping of product from the inventory either to wholesaler, retailer, customer that is it is the rate at which product shipped out from the stock. Stock is an accumulation of product in an inventory or integration of inflows and outflows (Sterman 2000). The mathematical equation of stock can be represented by:

$$
\operatorname{Stock}(t)=\int_{t_{o}}^{t}[\operatorname{Inflow}(s)-\operatorname{Outflow}(s)] d s+\operatorname{Stock}\left(t_{o}\right)
$$

where inflow(s) and outflow(s) represent the value of the inflow and outflow at any time $s$ between the initial time $t_{o}$ and current time $t$ respectively.

\section{SD method for analysis of manufacturing process}

Manufacturing processes are critical components of any production system. A manufacturing process exhibits the attributes and characteristics of a system. It can be viewed as the conversion of resources of materials, energy and information into finished products. Such a view focuses on the flows inside the manufacturing system. However, the manufacturing systems operating within factories are complex. The system composed of design, process planning (or machining strategy), machining, assembly, diagnostic and monitoring and also the interaction of manpower, tool, and material. The system is changing over time, so the changes that lead to any problematic behaviour is required to be identified. The manufacturing manger should analyse and trace the relationships between the manufacturing processing components that cause the changes.

Forrester considered SD to reflect a universal applicability to any situation which can be modelled as a 'system', which combines people and/or machines (Towill, 1993). SD is a useful tool for modelling and simulation of manufacturing processes and is still relevant as a dynamic-based industrial modelling technique. However, the application of SD in 
manufacturing processes has been less widespread and has gone into a lengthy slack period since developed. Its use in manufacturing shows a relative lack of exploitation especially at higher levels of modelling.

$S D$ offers the following benefit for modelling and simulation in manufacturing processes and recommended to use in areas (Aramburo et al., 2012; Azar, 2012; Bland, 2010; Brailsford et al., 2004; Sterman, 2000):

- SD integrates many subsystems to give an understanding on holistic view of the entire manufacturing system

- SD model provide a full picture on the qualitative and quantitative issues in manufacturing processes

- $\quad$ SD more focus on polices and strategic issues - this are the central focus in SD model

- the model allows the construction of the causal relationships and feedback effect between the manufacturing process parameters or variables or factors

- it provides a framework for understanding manufacturing process (system) composed of parts or elements that influence each other over time

- it provides an insight into understanding of the inner working of the dynamics of the complex manufacturing system

- to understand the behaviour of the complex system of manufacturing processes over time.

In spite evidence that SD appears to have not been applied to its full potential in manufacturing strategy scenarios. Considering the importance of improving the efficiency of manufacturing, the research presented in this paper demonstrates the application of SD to modelling of manufacturing processes.

The case studies following is aimed to model the processes (casting of cylinder head and machining of crankshaft), to understand energy consumption, losses during the process as well energy budget for the waste generated by the processes and to identify potential ways that improve energy efficiency of the process. To build an SD model of the given processes the approached illustrated in Figure 3 is followed.

The paper focus on:

- the material (any input to the system)

- the product( output from system)

- losses and waste from the system.

Figure 3 Modelling process approach to building SD model of the given process (see online version for colours)

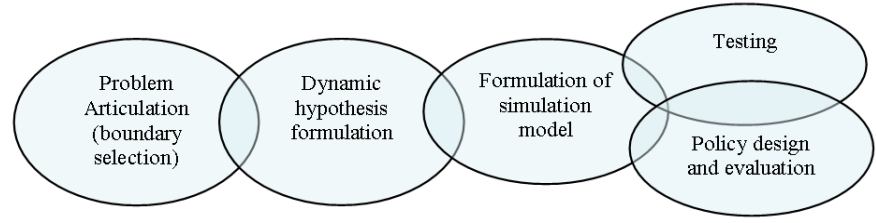




\subsection{Research method}

The approach following to conduct this study and to data collection for input to the SD modelling and simulation include:

- State the problem description - define the problem, understand process.

- State of the art related to research area is conducted.

- Company production line is studied - by following the steps in the production line, the flow of the processing steps is sketched, each operation is studied thoroughly: its input, output, and possible losses (waste), factors influencing, surrounding temperature of the production line, time, etc.

- Questionnaires are prepared in the excel sheet format - some of the questionnaires includes information on energy input and consumption on each operation, capacity of each machine and ladle, operation and working time, type of material, working/ operating temperature, process input/output, etc. Moreover, interview has also been done.

- At the last, information during study of the production line, from interview, questionnaires and literature has been collected and analysed.

\section{Examination of the production process - casting and machining}

\subsection{Casting of cylinder head}

Casting, the products of the metal foundry industry, is used to produce a wide variety of metal components or parts with complex geometries. In which these parts can vary significantly in size and weight ranging from a couple of ounces to several tones. Metal casting involves melting the material and pouring the molten metal into moulds to produce cylinder head. The overview of the 'sand mould casting' process for cylinder head production studied in this research is shown in Figure 4:

Figure 4 Overview of the 'sand mould casting' process steps for cylinder head production

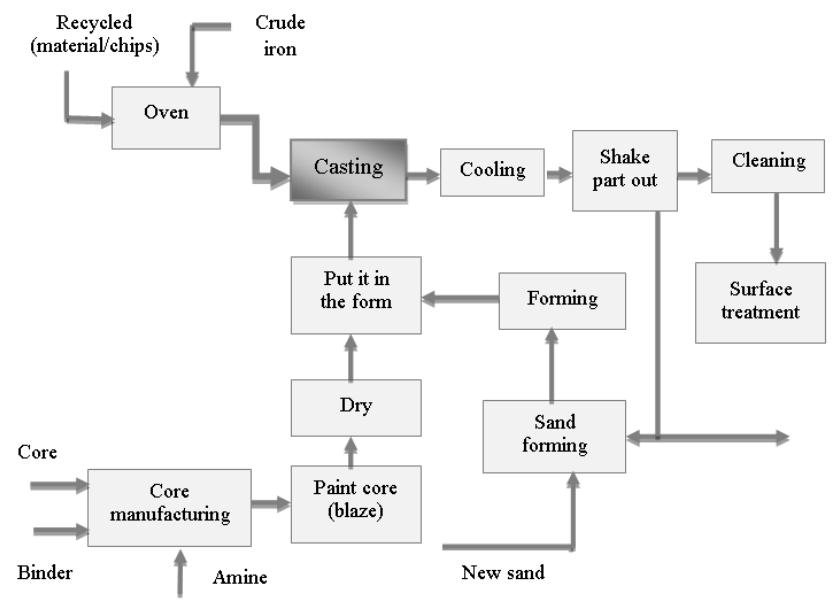


Figure 5 Process energy consumption in metal casting (see online version for colours)

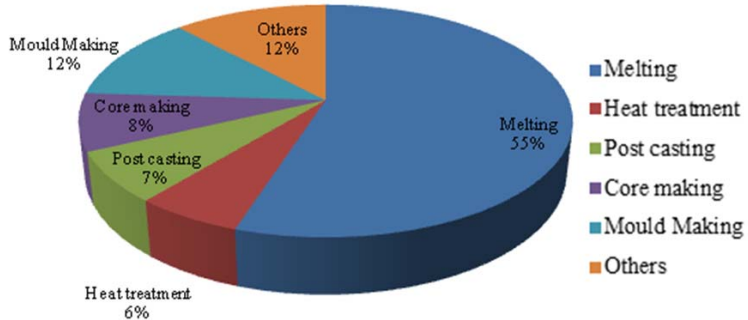

The energy efficiency of any foundry largely drives on the efficiency of the melting process. Although the energy consumption in the melting process has been a significant concern in foundry operations, the industry would like to use melting technologies with low energy efficiencies. Robert et al. (2005) explained the steps used in melting of any industrial metal used in manufacturing, as well these are the steps considered through this research work.

1 preparing the metal and loading

2 melting the metal

3 refining and treating molten metal

4 holding molten metal

5 tapping molten metal

6 transporting molten metal.

\subsection{Machining of crank shaft}

The crankshaft is machined through different processes. The initial forged part, which is received from supplier, goes through the following processes steps until it is ready to be assembled into an engine:

1 milling the length

2 rough machining (done dry)

3 rough milling

4 rough drilling (done with cutting fluid)

5 rough turning

6 balancing the crankshaft

7 blasting

8 rough grinding

9 turning (dry) 
10 milling

11 drilling oil holes

12 washing after hole making process

13 surface hardening

14 pressure rolling

15 alignment checking and correction

16 fine grinding

17 cold rolling of splines

18 turning

19 balancing by removing material

20 non-destructive testing (NDT)

21 polishing (fine polishing on bearings)

22 final wash

23 final measurement

24 final check.

Figure 6 Machining steps of crankshaft (see online versions for colours)

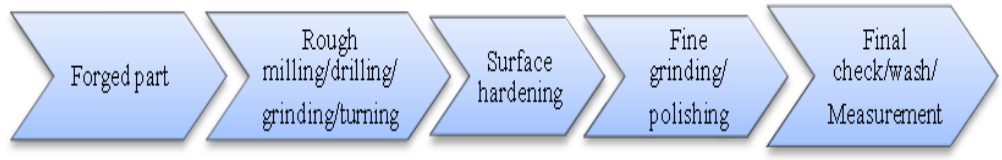

Steps of machining studied in this research can be divided into three main groups as shown Figure 6; rough machining operations, surface hardening and fine machining operations to make sure all specifications are met. Final checks, wash and measurement are the final steps in the cylinder production line.

\section{Application of SD simulation and modelling in production process}

Two cases have been investigated in two automotive factories in Sweden. The first case is casting of a cylinder head and the second is machining of a crankshaft. The objectives to use SD simulation modelling are:

- to analyse the energy input, consumption and losses in the system

- to identify the process having the highest energy consumption rates in the production system

- $\quad$ to understand the intricate nature of the interrelated of process parameters and to make decision about (regarding) minimising energy losses in the system. 


\subsection{Casting of cylinder head}

This research does not consider all manufacturing steps of cylinder head shown on Figure 4. Instead it considers the main energy intensive steps in casting cylinder head processing. For detail is presented in Section 6.1.1

\subsubsection{Identifying most energy intensive operations}

Casting is one of the most energy intensive processes in manufacturing and it is also an area where energy waste/lost is quite high. In order to concentrate on the most energy intensive steps (processes) for cylinder head casting the following approach is followed as illustrated in Figure 7:

- identify all operations - by following the steps in the production line during production, and collecting input/output process data obtained from the company

- identify operations that constitute the highest percentage of energy consumption based on input/output process data from company and supported by literature survey

- identify factors that influence each operations - by studying the production line, literature survey, input/output process data from company

- $\quad$ select the major energy intensive operation.

Figure 7 Steps to identifying the main energy intensive steps in cylinder head casting (see online version for colours)

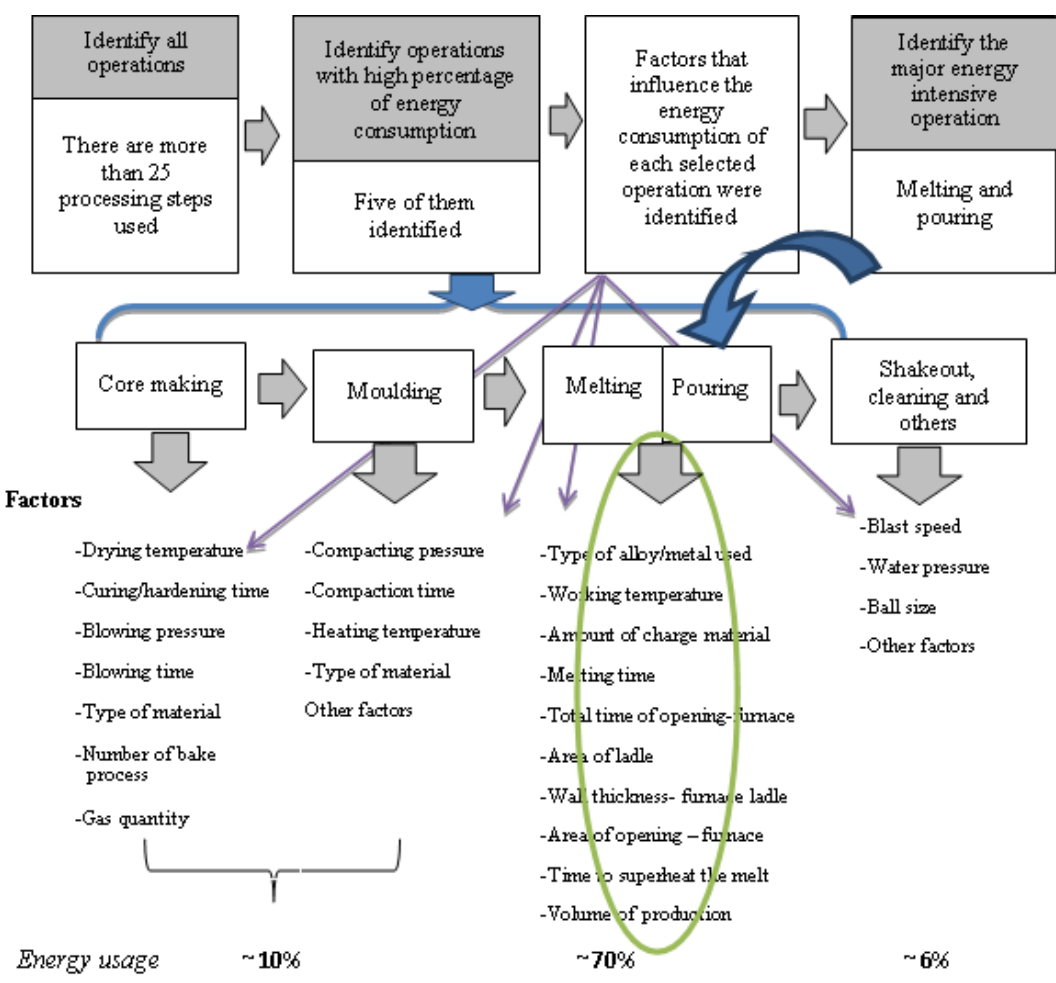


The findings from investigation suggest that melting, holding and pouring are the prominent energy intensive steps in cylinder head casting. Amongst, melting and pouring accounts about $70 \%$ of the total energy consumption, in which melting process comprising for about $55 \%$ of the energy as shown above Figure 5 (Chittum et al., 2010; EECA, 2009; IEA, 2008; USDOE, 2008).

\subsubsection{Identified critical operations and influential parameters}

As briefly described in Section 6.1.1, the parameters that influence the energy consumption in melting, holding and pouring processes have been identified. These parameters are:

- furnace opening time

- factor of radiation

- black body radiation

- area of opening in the furnace enclosure

- emissivity of material

- amount of charge material in the furnace

- wall thickness and door width

- operating temperature

- average surface temperature

- area of hearth, ceiling, and wall

- melting time

- holding time of ladle

- conduction heat transfer through refractory lining (refractory thickness, area of ladle, temperature of hot and cold surfaces)

- emissivity of radiating body

- thermal conductivity of material.

\subsubsection{Energy input, consumption and losses in melting, holding and pouring}

Every process consists of basic elements of input and output. The inputs and output to the process (melting furnace) are:

- energy - derives its heat from natural gas, fuel, electricity, and coke

- air

- fluxes and alloy elements

- base metals

- molten metal, dross or slag, fuel gas. 
Ideally, all heat added to the furnaces is used to heat up the load or stock. In practice, however, 20 to $50 \%$ of the energy consumed is lost via conduction, convection and radiation, as well from waste heat contained in streams of hot liquids, flue gases, and slags as shown in Figure 8. The outputs from the system are molten metal, dross or slag, fuel gas.

In modelling, the total heat required in the process is estimated as the sum of the energy needed for melting, pouring and holding.

Figure 8 Process input, output and losses/wastes (see online version for colours)

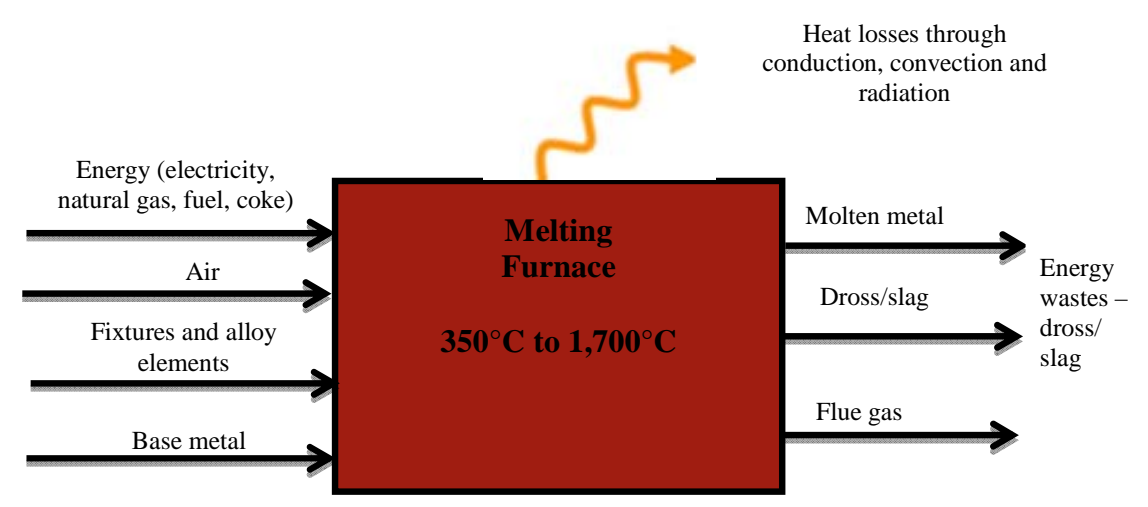

\subsubsection{Possible heat losses}

Heat supplied in the furnace is wasted in different ways; approximately 40 to $60 \%$ of the energy input in the company is lost as waste heat. Moreover, these loses are depend upon the factors or parameters associated with the operation and/or the design of the furnace. The Sankey diagram in Figure 9 shows the possible ways of energy losses in the process; correspondingly Figure 10 illustrates factors in some of the possible heat losses in melting and pouring. From the total energy input, i.e., gross input only small percentage of heat is used to melt the material, i.e., useful output (called heat to load).

Figure 9 Sankey diagram - possible heat losses in industrial heating processes

Losses due to delay

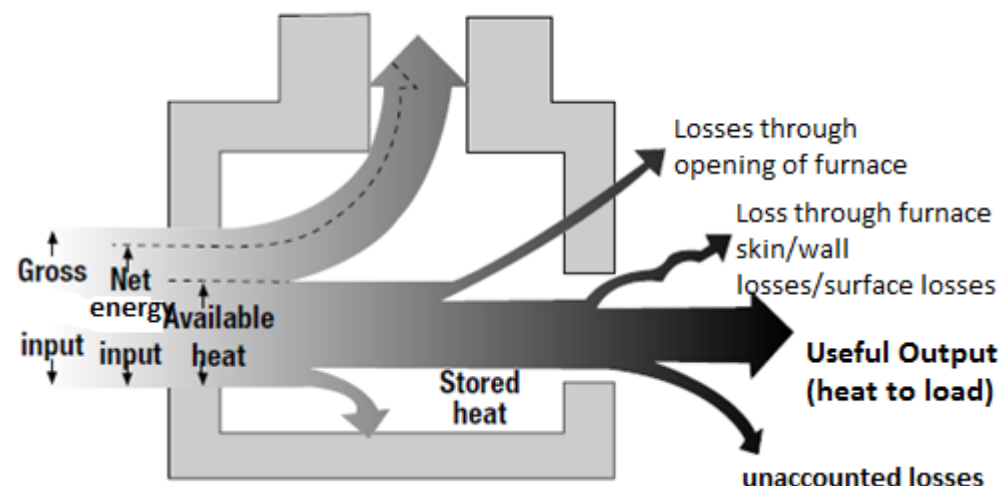


Figure 10 Factors in some of the possible heat losses

\begin{tabular}{|l|}
\hline \multicolumn{1}{|c|}{ Loss through opening } \\
\hline -Total time of opening \\
-Factor of radiation \\
-Black body radiation \\
-Area of opening \\
-Emissivity of material \\
-Amount of charge \\
material \\
\hline
\end{tabular}

\begin{tabular}{|l|}
\hline \multicolumn{1}{|c|}{$\begin{array}{c}\text { Loss through furnace } \\
\text { wall/skin }\end{array}$} \\
\hline Furnace ceiling, hearth and \\
wall \\
-Surface area, heat loss per \\
area, average surface \\
temperature
\end{tabular}

Figure 11 Stock and flow model for casting of cylinder head - melting and pouring (see online version for colours)

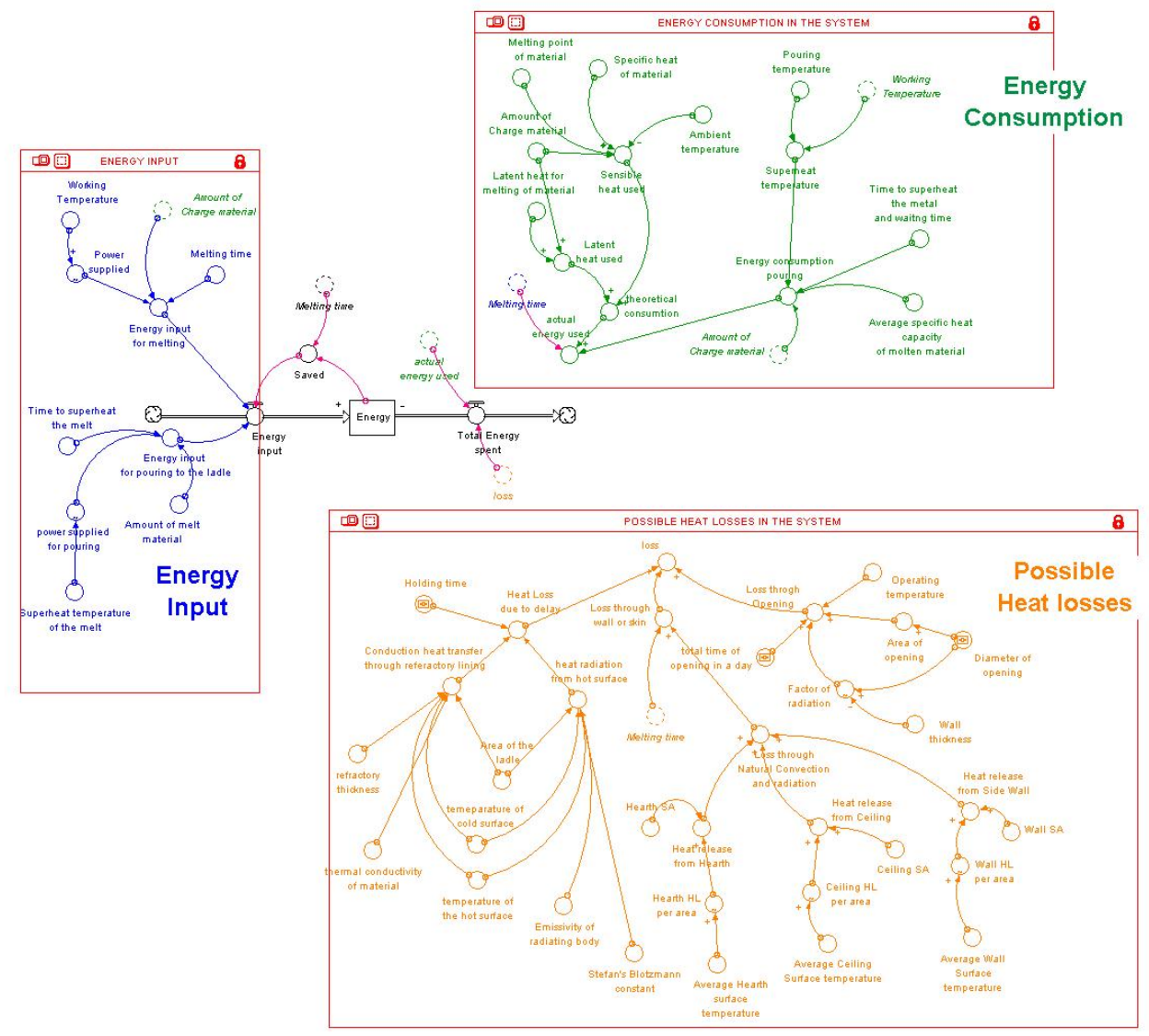


Figure 12 Stock and flow model for casting of cylinder head - melting and pouring including structural material as input (see online version for colours)

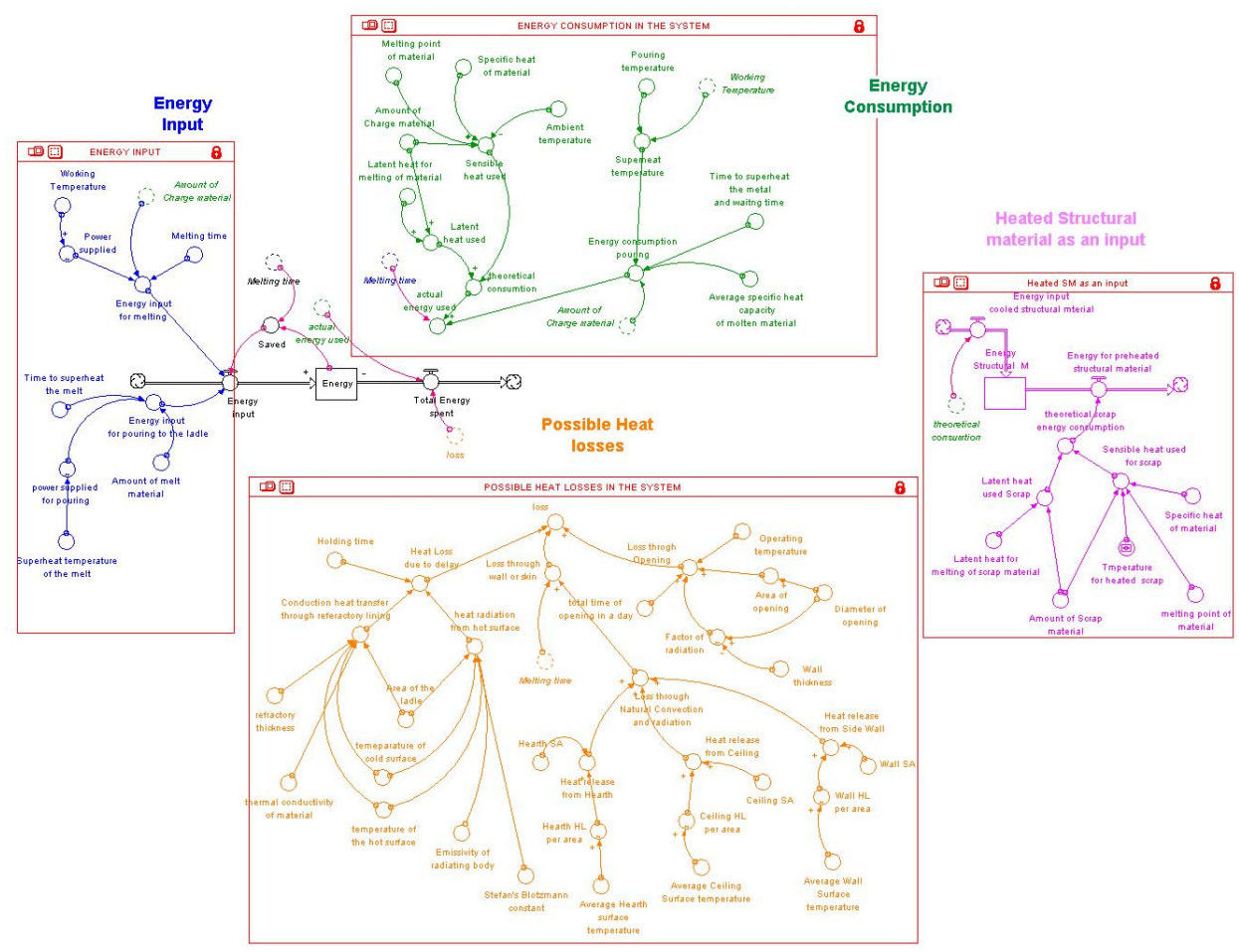

\subsubsection{Heated structural material as input}

When the cast solidifies, the mould is knocked out before cooling. Then the feeder and gating system (inlet) of the casting is trimmed by some mechanism. These hot scrap materials are reused as an input in the sand casting process, and hence the scrap for the next cycle can be considered as preheated or heated scrap.

This concept is included in the model as 'heated scrap material as an input' and possibly to recover energy in the system. The parameters include:

- latent heat for melting of scrap material

- amount of scrap material

- ambient temperature/temperature of preheated scrap

- melting point of material

- specific heat of material

- time.

The key parameters that influence these processes and their relationships for energy consumption and dissipation have been mentioned and explained earlier in Section 6.1.2. Using SD simulation and modelling, the parameter relationships and interactions in the system are modelled. 


\subsection{Machining for crankshaft production}

In terms of annual money spent, machining is one of the most important manufacturing processes due to the high volume machining performed in industry. As a result, sustainable machining can bring economic and environmental benefits. In the case of the crankshaft, there are different machining operations involved. In this case study, the most frequently used machining operations (steps) that are shown in Figure 6 is considered. Since turning, milling and drilling constituted a relatively large percentage of the operations (and therefore a large part of energy consumption - according to input/output process data from the company) they were chosen for modelling.

\subsubsection{Process input, output and losses}

In the case of crankshaft machining, the system can be represented by the following diagram and parameters.

Figure 13 Schematic representations of system input and output

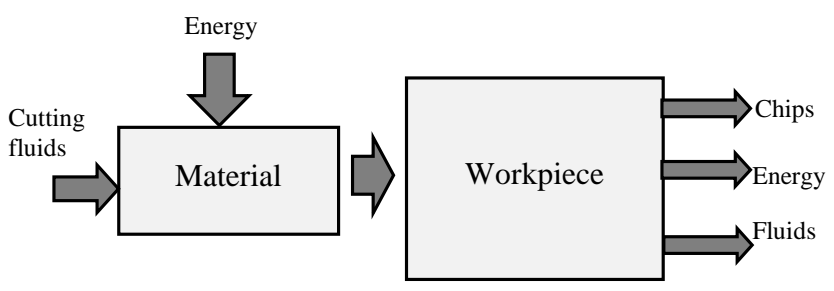

Source: Nafisi (2012)

The inputs to the process are:

- $\quad$ work piece material

- $\quad$ cutting fluids that are used in machining

- $\quad$ energy needed to perform the machining.

The output of the system is:

- the final work piece

- $\quad$ the chip that is produced - a part of it is recycled and the rest is a waste

- $\quad$ the fluids that are wasted - a part of the fluid which was used is recycled but part of it cannot be recycled and there is some evaporation as well

- $\quad$ the energy which was wasted - it can also be called non-value adding energy.

\subsubsection{Possible energy losses}

The models that have been developed contain sections dealing with chip generation, cutting fluid usage and recycling and total energy consumption. In these models total energy comprises of: 
- $\quad$ energy consumed in machining operation

- $\quad$ energy consumed to recycle fluids

- material

- $\quad$ energy consumed for rework and

- $\quad$ energy wasted due to non-value adding activities.

As a matter of fact, in reality only the non-value adding activities can be eliminated, or minimised, since to perform machining it is necessary to have other types of energy consumption. It is necessary to identify parameters that have a role on energy consumption to form the model.

\subsubsection{Identified critical steps and influential parameters}

Non-value adding activities in a machining process are those activities that are carried out but actually do not contribute to the cutting process directly. Machine downtime, traverse time, tool disturbances, parameter resetting time, tool change time are relevant non-value adding parameters. These parameters contribute to the so called energy loss.

The following parameters determine how much energy is going to be consumed in the machining process:

- $\quad$ work piece length

- $\quad$ spindle speed

- feed per revolution

- $\quad$ specific cutting force

- $\quad$ work piece diameter

- depth of cut.

In this case, these parameters are referred to as process level parameters.

Pumping fluids to the process and recycling fluids and material from the process also consume energy and therefore are taken into account. Some of the relevant parameters are chip recycling rate, fluid flow rate, energy to recycle one litter of fluid and energy to pump one litter of fluid. They are referred to as system level.

It is assumed that the energy supplied to the system is unlimited, in the sense that it is supplied at a constant input rate and is never less than the total energy consumption of the system.

Parameters that are influential in energy consumption are identified. A scenario analysis verifies their selection. The overall model that is developed using SD captures these parameters and their relationships.

The complete model is depicted in Figure 14. 
Figure 14 Stock and flow model for crankshaft machining (see online version for colours)

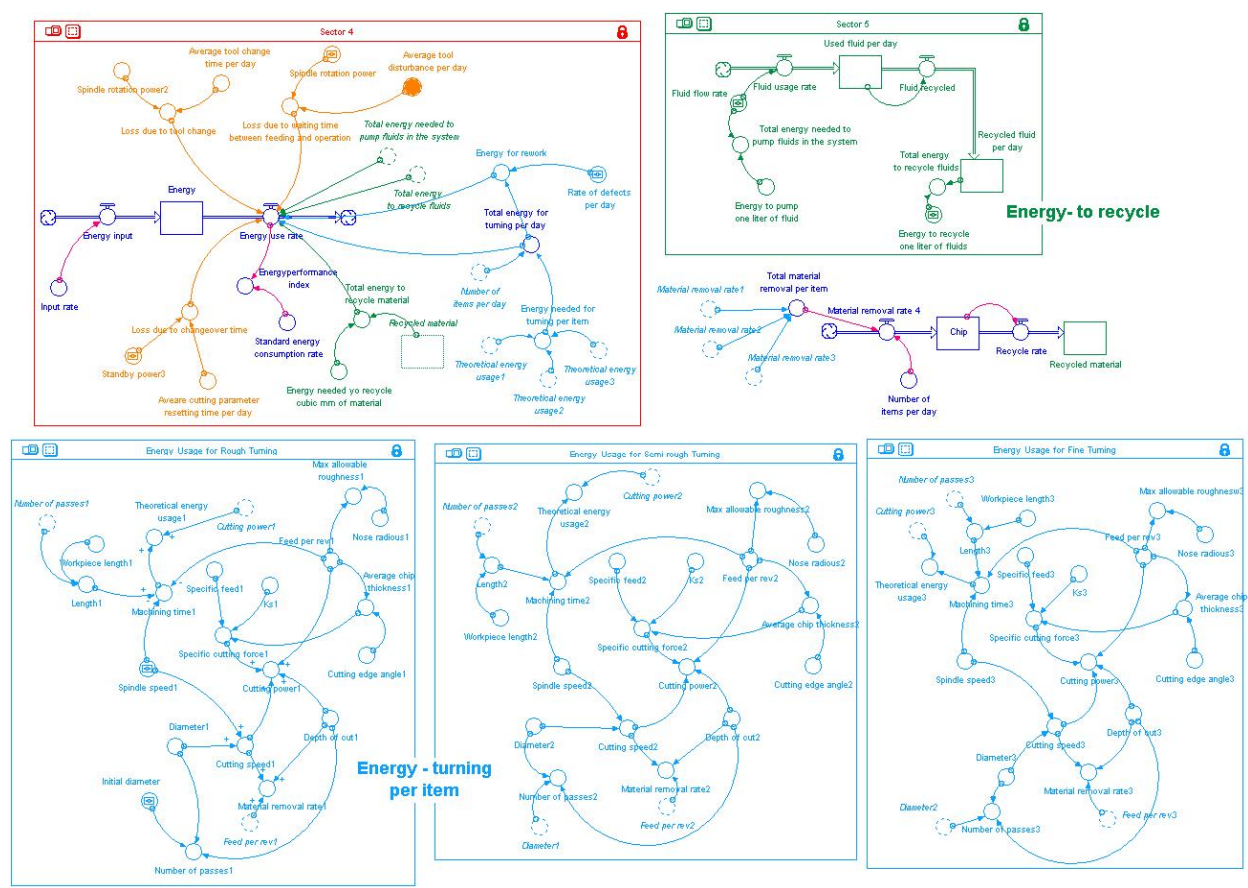

\section{Results and discussion}

As it has been discussed earlier, the purpose of the SD modelling and simulation is to reveal how the technical and policy-based decisions will affect the energy consumption and how a control strategy of the energy consumption will be implemented. It has to be pointed out that SD simulation of the present production process will neither used for the prediction of the future energy levels nor for quantitative estimation of the energy consumption.

Results are obtained by initialising the simulation model variables and running the simulation with the given process input/output data from the company.

\subsection{Casting of cylinder head production - case one}

A possible approach is proposed to improving overall energy efficiency:

1 prevent the losses

2 capture and reuse the waste heat - close the loop by using heated structural material as an input to the system. 


\subsubsection{Prevent losses}

Figure 15 displays the results for the amount of energy input, actual energy used and losses in the system; obtained by initialising and running the simulation model factors (those identified earlier - see Figures 7 and 10) with the given data from the company.

Figure 15 Simulation result for energy input, consumption, losses - cylinder head (see online version for colours)

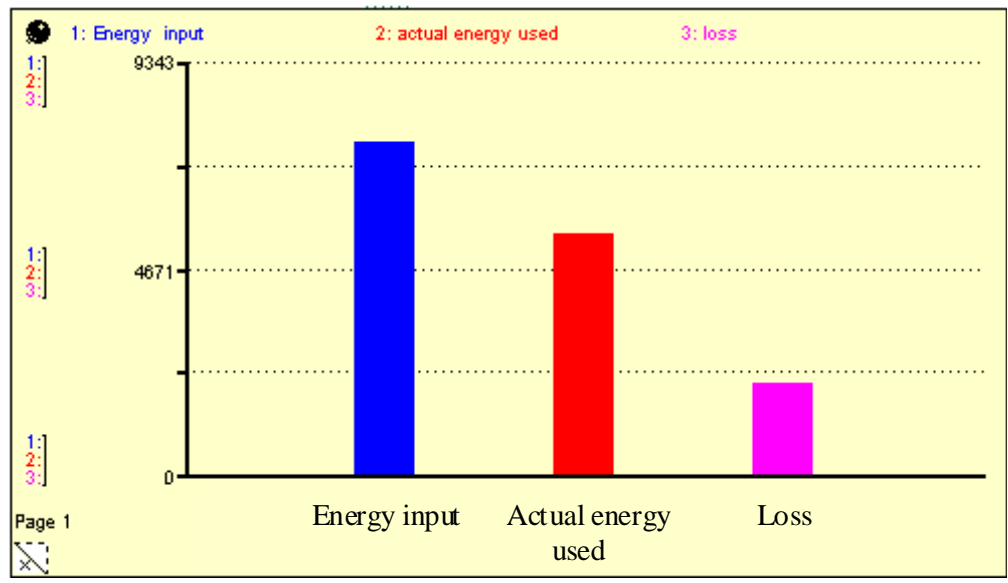

The total energy input is the sum of actual energy used and total losses. The loss shows the total possible ways of heat losses during melting and superheating.

Figure 16 Comparison of different ways of heat losses- cylinder head (see online version for colours)

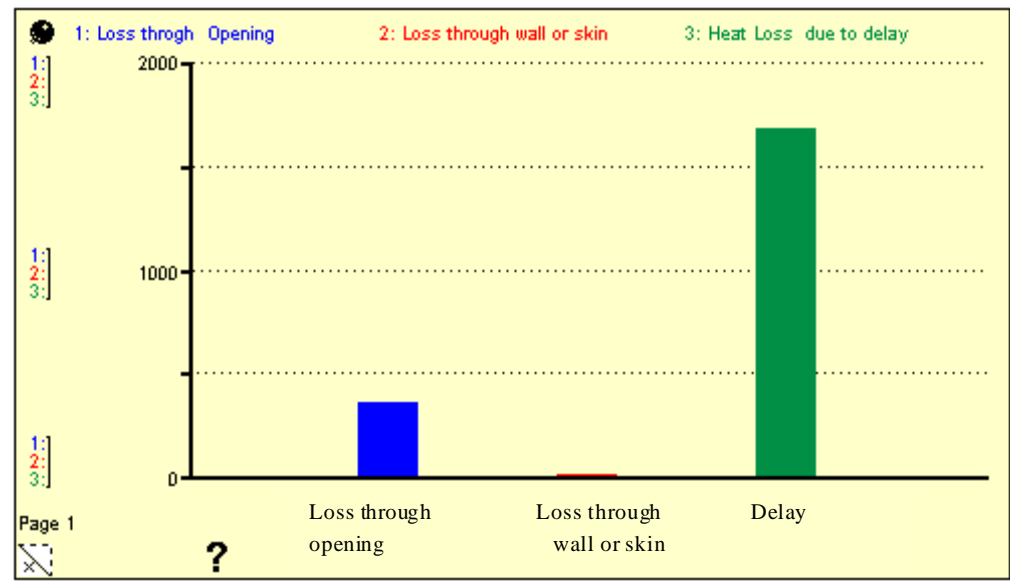

To compare the level of the different ways of heat losses in the system (those explained in Section 6.1.4.), only the simulation result for losses is depicted as shown Figure 16. 
From the figure it can be seen that the heat loss through wall is very small as compared to heat losses due to delay and losses through opening in furnace door; it can even be neglected. But if it stands alone, it will have a higher impact in the process. It appears that heat loss due to delay is the highest proportion of heat losses in the system; it is then followed by losses through opening of the furnace door and losses through natural convection and radiation. To detect the parameters which have the highest impact on the heat losses in the process, we scrutinise the parameters of heat losses through delay and opening only. In the given scenario this is a reasonable approach as losses through the wall or skin are almost negligible.

The result from simulation aids to detect possible areas in the system that has the potential to minimise energy losses (consumption). Parameters that have the highest impact in energy consumption have been identified. Among them holding time (delay), area of opening, time of opening and scrap temperature account for highest energy consumption. In the simulation control panel shown below in Figure 17, there is a slider that makes it easy to conduct simulation experiment. This is done by varying the value of parameters which impact energy consumption in the system most. Results are displayed in the graph and the exact value is shown in the table.

In the future, if there is a possibility for the company to change the values of the parameter (for example, reduce the time of opening of the furnace during melting, holding time, etc.), it can easily see how the other parameters and energy level are changed as all the system elements are interacted each other over time. This is results in the dynamic complexity of the system as defined earlier.

By changing the values of a parameter in the model, the other parameters also changed as the system interconnected each other. Moreover, the values of energy losses, saved, consumption can be read on the table and graph. Thus the possible energy saving areas that result from this simulation model can be identified.

Figure 17 Simulation run for energy input, consumption, losses model - cylinder head (see online version for colours)

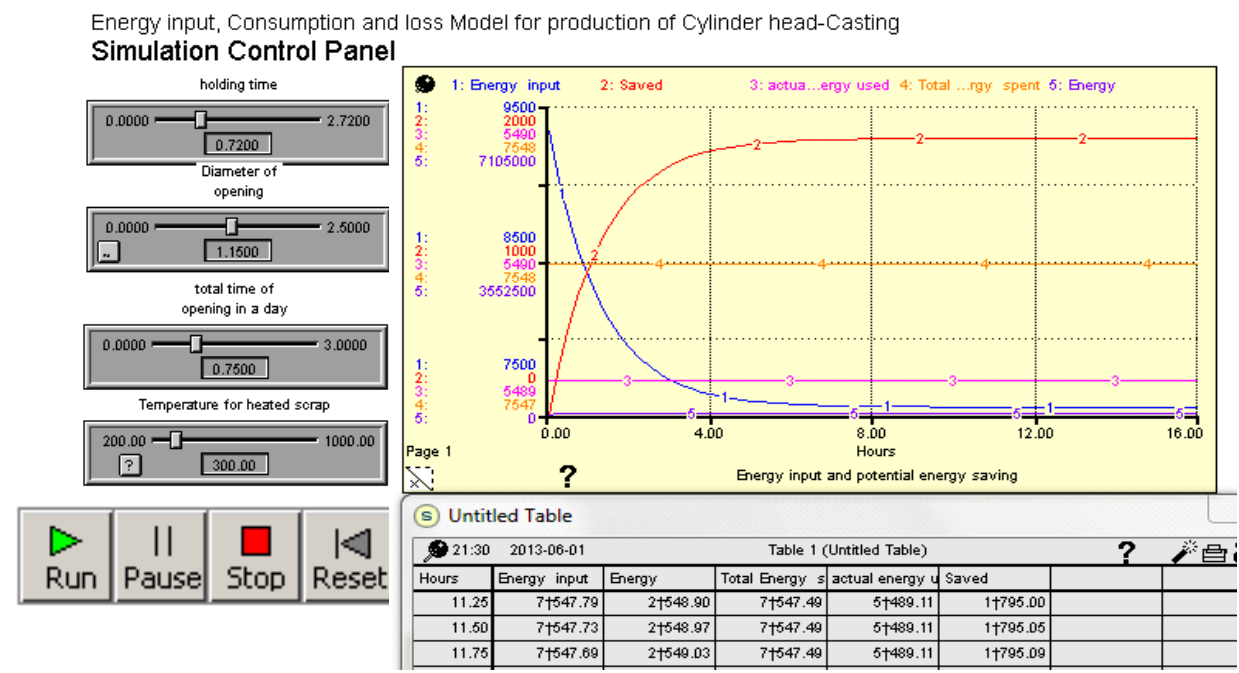


Figure 18 Simulation result - comparison: reducing holding time of the melt by $25 \%$ and $40 \%$ (see online version for colours)

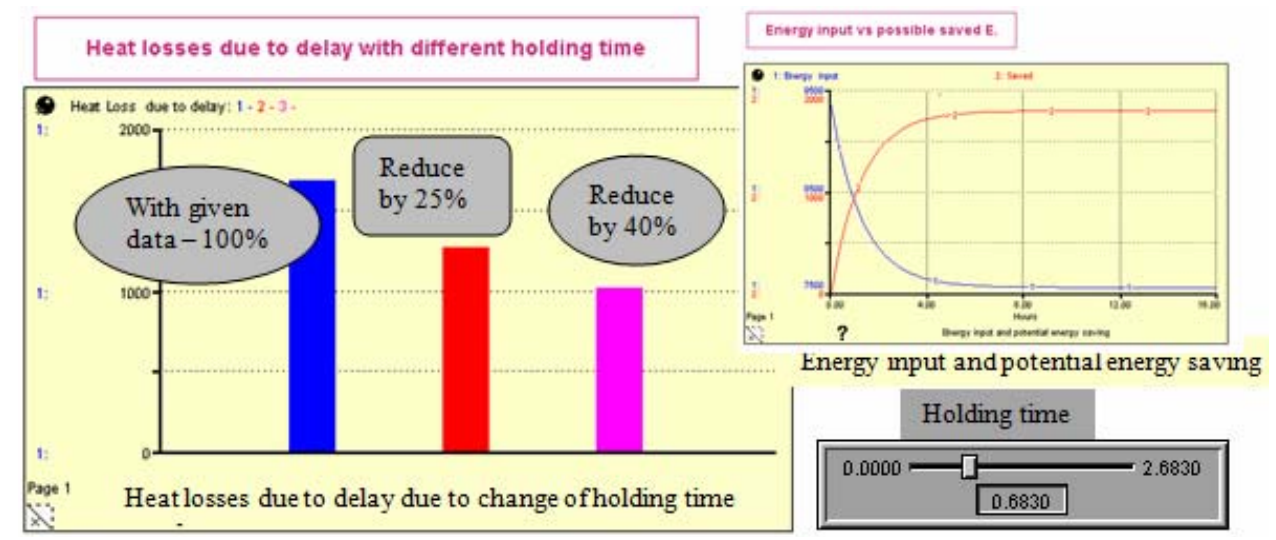

1 Holding time: Reducing the holding time of the melt in the ladle for example by $25 \%$ from the given measured value (25\% from the initial value), will reduce the energy loss in the system by $40 \%$ from the average loss. Similarly, if the time delay is decreased by $40 \%$, the energy loss will be reduced by $80 \%$. This is one potential area for reducing energy losses in the system. See Figure 18 for the comparison of simulation result when the holding time reduced by some percentage value. Here the thing that need to give attention is that changing in one parameter does not mean that freezing others, but a change in one result a change on others as the parameter (system element) interact each other over time.

2 Area and time of opening: The simulation result shows, increasing or decreasing the opening time of the furnace for example by $30 \%$ will increase or decrease the energy loss by $30 \%$ from the average opening time energy loss. For example through melting, if the furnace opening time is $0.75 \mathrm{hr}$, minimising it by $33 \%(0.65 \mathrm{hr})$ reduces the energy loss by $33 \%$.

In other words, if the area of opening of the furnace is either decreased or increased by $21.7 \%$ in diameter, the energy loss due to opening is decreased by $38.7 \%$ and increased by $48.2 \%$ from the normal opening area of energy loss respectively.

3 Scrap temperature: The higher scrap temperature, the greater possibility to reduce energy consumption in the process.

Holding time (time delay) and temperature of the scrap material (structure of the mould after casted part is separated) has the highest impact on improving energy consumption (can improve energy efficiency). Almost 1/3 of the energy losses in the melting process are caused by the delay. For example, from it is possible to save about 1,321,200 KJ of energy if the delay is reduced (current average delay for the company is about 40 minutes) by 10 minutes.

In cylinder head production, $60 \%$ of the volume of a mould accounts for the cylinder head and remaining $40 \%$ is structure of the mould (gates, runners, risers, etc.). Currently, the mould is cooled down to the ambient temperature and mould structure is separated 
from the cylinder head and then recharged (after primary treatment and pre-heating) in the furnace for re-melting. If the mould structure is separated from the cylinder head at higher temperature (not waiting until it reaches to ambient temperature) substantial amount of energy could be saved. For instance, simulation result suggest that with the current capacity of the melting process for each $10^{\circ} \mathrm{C}$ of recovered heat can save up to 460,800 KJ energy.

Though cost is not considered as a modelling parameter, it can be easily estimated that an increase in energy consumption will increase the cost and if energy is reduced cost will also be reduced.

\subsubsection{Machining of crankshaft}

Obtained diagrams are indicators of system's behaviour. As shown in Figure 19, stocks are represented by graphs which clearly exhibit the trend that stocks take over simulation length. Energy consumption, fluid consumption and chip generation are the stocks which are investigated.

Figure 19 Simulation run and result - machining (see online version for colours)
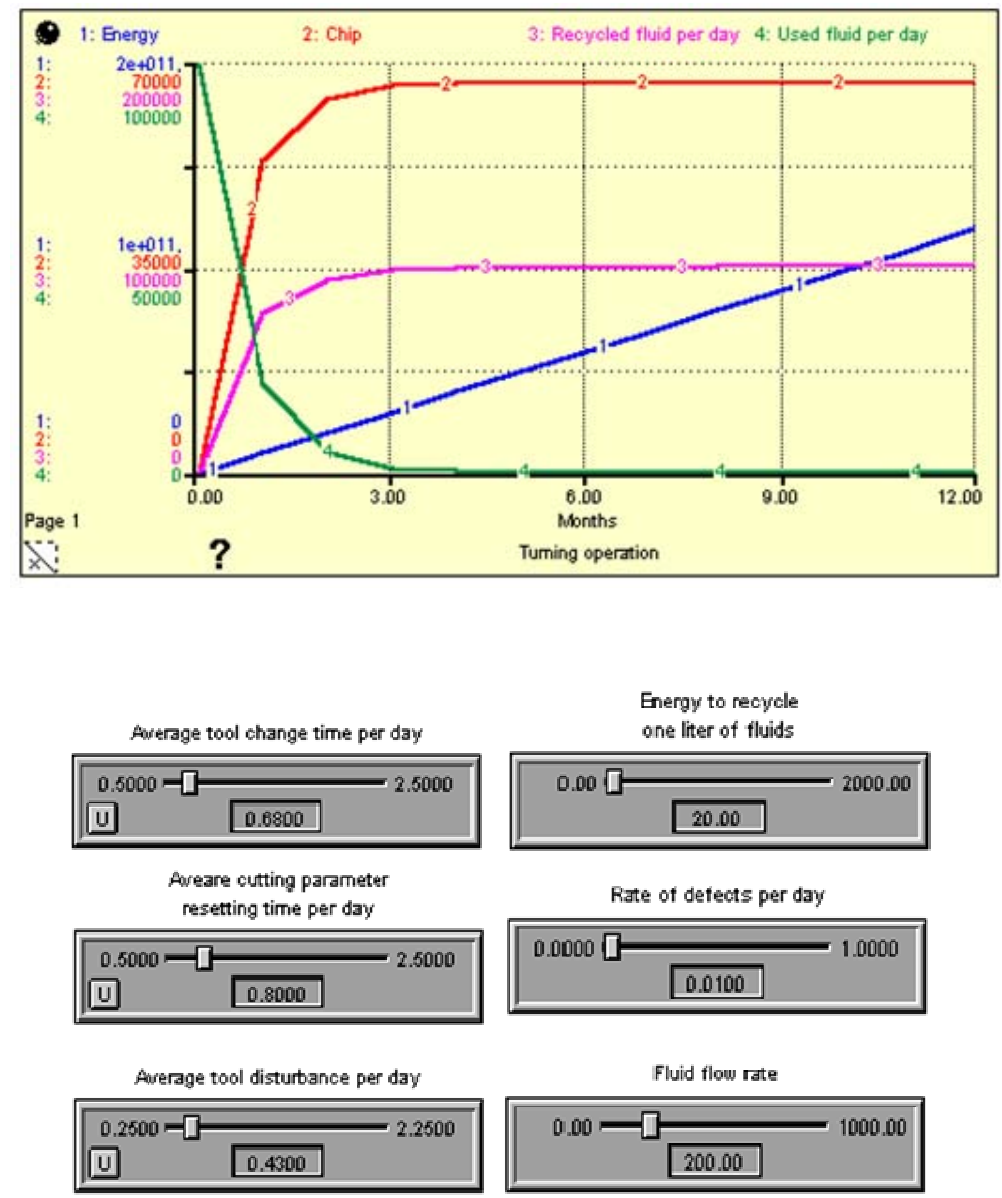
Through modelling and simulation results are studied and show the dynamic behaviour of the model. Energy consumption, fluid consumption and chip generation are taken into account.

During simulation, some scenarios are developed to check the result of changing parameters on energy consumption. As a result it becomes clear that not all factors considered in modelling have an influence on energy consumption. Process level parameters turn out not to be influential while system level parameters appear to be quite influential.

To improve these processes energy-wise, one can suggest non-value adding activities to be as small as possible. In this case, average tool change time, average cutting parameters resetting time and average tool disturbance time can be minimised. Speaking of the system level, turning to new methods to treat chip and fluid, using new technologies and cutting tools to allow minimum quantity lubrication and improving item quality can significantly reduce energy consumption.

\section{Conclusions}

In order to make sound decisions regarding the efficient use of manufacturing resources, companies need reliable models that allow efficient simulation of the components in the manufacturing processes. Thereby, factors contributing to the material and energy loss can be identified.

Using SD approach, the interaction between factors in the overall manufacturing system is analysed with respect to energy consumption, losses during the process as well waste generated by the processes. By varying (changing) values of the parameters that have the highest impact in the process, the breakthrough opportunities that might dramatically reduce energy consumption during melting, holding and turning are explored, and potential energy-saving areas are also identified. SD simulation by itself does not give the 'best' solution. SD simulation provides information regarding how the system responds to various conditions. The two cases studies consider step by step the model formulation and analyse in depth the factor contributing to the energy losses.

The results from this research work are intended to aid companies in systematically evaluating current working system and to designate potential avenues the changes that made dynamically to minimise energy usage in the production and hence become sustainable manufacturing.

\section{Acknowledgements}

The case studies presented in journal is part of the project called FFI. The authors would like to express their gratitude to VINNOVA, Sweden for granting this research. The authors would like also to thank all reviewers for the invaluable feedback and comments they have made to make this journal paper possible. 


\section{References}

Aramburo, S.A., Castañeda Acevedo, J.A. and Morales, Y.O. (2012) 'Notes and insights: laboratory experiments in the system dynamics field’, System Dynamics Review, Vol. 28, No. 1, pp.94-106.

Azar, A.T. (2012) 'System dynamics as a useful technique for complex systems', International Journal of Industrial and Systems Engineering, Vol. 10, No. 4, pp.377-410.

Baines, T.S. and Harrison, D.K. (1999) 'An opportunity for system dynamics in manufacturing system modeling’, Production Planning and Control: The Management of Operation, Vol. 10, No 6, pp.542-552.

Baines, T.S., Harrison, D.K., Kay, J.M. and Hamblin, D.J. (1998) 'A consideration of modelling techniques that can be used to evaluate manufacturing strategies', The International Journal of Advanced Manufacturing Technology, Vol. 14, No. 5, pp.369-375.

Bland, W.S. (2010) System Dynamics System Dynamics: Solving Problems Using a 'System of Systems' Approach [online] http://www.mors.org/UserFiles/file/2010\%20Personnel/ Tutorial\%203\%20Bland\%20cleared.pdf (accessed November 2010).

Brailsford, S. and Hilton, N. (2001) 'A comparison of discrete event simulation and system dynamics for modelling health-care systems', in Riley, J. (Ed.): Proceedings of the 26th meeting of the ORAHS Working Group 2000, pp.18-39, Glasgow Caledonian University, Glasgow, Scotland.

Brailsford, S.C., Lattimer, V.A., Tarnaras, P. and Turnbull, J.C. (2004) 'Emergency and on-demand health care: modelling a large complex system', Journal of the Operational Research Society, Vol. 55, No. 1, pp.34-42.

Brundtland, G. (1987) Our Common Future: The World Commission on Environment and Development, Oxford University Press, Oxford.

Camdali, U. and Tunc, M. (2006) 'Steady state heat transfer of ladle furnace during steel production process', Journal of Iron and Steel Research, International, Vol. 13, No. 3, pp.18-20.

Chittum, A.K., Neal, E.R. and Nate, K. (2010) 'Trends in industrial energy efficiency programs: identifying today's leaders and tomorrow's needs', Thirty Second Industrial Energy Technology Conference, American Council for Energy-Efficient Economy, New Orleans, LA.

Crespo-Márquez, A., Usano, R.R. and Aznar, R.D. (1993) 'Continuous and discrete simulation in a production planning system: a comparative study’, Proceedings of International System Dynamics Conference, Cancun, Mexico, The System Dynamics Society, p.58.

EECA (2009) 'Heat recovery applications', in EECA (Ed.): Technical Guide, Vol. EEC1045, EECA Business, Wellington.

Ford, A. (2009) Modeling the Environment, Island Press, Washington, DC.

Forrester, J.W. (1961) Industrial Dynamics, MIT Press, Cambridge, MA.

IEA (2008) Worldwide Trends in Energy Use and Efficiency Key Insights from IEA Indicator Analysis, OECD/IEA, Paris.

Kibira, D., Shao, D. and Tina Lee, Y. (2009) 'Modeling and simulation analysis types for sustainable manufacturing', Proceedings of the 10th Performance Metrics for Intelligent Systems Workshop, MD, USA, September 2010, pp.69-76.

Kirkwood, C.W. (2013) System Dynamics Methods: A Quick Introduction [online] http://www.public.asu.edu/ kirkwood/sysdyn/SDIntro/SDIntro.htm (accessed January2013).

Lane, D.C. (2000) You Just Don't Understand Me: Models of Failure and Success in the Discourse Between System Dynamics and Discrete Event Simulation, London School of Economics and Political Sciences.

Leemis, L. and Steve, P. (1994) Discrete-Event Simulation: A First Course, The College of William and Mary, Williamsburg, VA, USA. 
Lin, C., Baines, T.S., J. O'Kane and D. Link (1998) 'A generic methodology that aids the application of system dynamics to manufacturing system modeling', International Conference on SIMULATION, IEE, Staffordshire University, UK.

Maani, K.M. and Cavana, R.Y. (2007) System Thinking, System Dynamics: Managing Changes and Complexity, 2nd ed., Pearson Education, Canada.

Mak, H-Y. (1993) System Dynamics and Discrete Event Simulation Modelling, PhD thesis, London School of Economics and Political Science, University of London, London.

Meadows, D.H. (1980) The Unavoidable A Priori. Elements of the System Dynamics Methods' Jorgen Randers, Cambridge, Productivity Press.

Nafisi, M. (2012) Applying System Dynamics Modeling to a Manufacturing Process with Regards to Environmental Friendliness and Energy Efficiency, Master's thesis, KTH Royal Institute of Technology, Stockholm, Sweden.

Özgün, O. and Barlas, Y. (2009) 'Discrete vs. continuous simulation: when does it matter?', Proceedings of the 27th International Conference of the System Dynamics Society, Albuquerque, NM, USA.

Robert, D.N., Kwon, J.Y., Majumdar, R. and Choate, W.T. (2005) Advanced Melting Technology: Energy Saving Concepts and Opportunities for the Metal Casting Industry, BSC Incorporated.

Sterman, J.D. (2000) Business Dynamics: System Thinking and Modeling for a Complex World, Irwin/McGraw-Hill, Boston.

Sweetser, A. (1999) 'A comparison of system dynamics (SD) and discrete event simulation (DES)', Proceedings of 17th International Conference of the System Dynamics Society and 5th Australian \& New Zealand Systems Conference, Wellington, New Zealand, 20-23 July, The System Dynamics Society.

Sweetser, A. (1999) 'A comparison of system dynamics and discrete event simulation', in Cavana, R.Y., Vennix, J.A.M., Rouette, E.A.J.A., Stevenson-Wright, M. and Candlish, J. (Eds.): Proceedings of 17th International Conference of the System Dynamics Society and 5th Australian \& New Zealand Systems Conference, System Dynamics Society, Wellington, New Zealand.

Tako, A.A. and Robinson, S. (2009) 'Comparing model development in discrete event simulation and system dynamics', Proceedings of the 2009 Winter Simulation Conference, pp.979-991.

Tesfamariam, D. and Lindberg, B. (2005) 'Aggregate analysis of manufacturing systems using system dynamics and ANP', Computers \& Industrial Engineering, Vol. 49, No. 1, pp.98-117.

Towill, D.R. (1993) 'System dynamics background, methodology and applications', Computing and Control Engineering Journal, Vol. 45, No. 6, pp.261-268, University of Wales College of Cardiff.

USDOE (2008) Waste Heat Recovery: Technology and Opportunities in US Industry, I.T.P.I. US Department of Energy's Office of Energy Efficiency and Renewable Energy, US Department of Energy. 